\title{
Optimising Bacterial DNA Extraction from Faecal Samples: Comparison of Three Methods
}

\author{
Birgitte Smith ${ }^{1}, \mathrm{Nan} \mathrm{Li}^{1,+}$, Anders Schou Andersen ${ }^{1,2}$, Hans Christian Slotved ${ }^{1}$ and \\ Karen Angeliki Krogfelt ${ }^{1, *}$ \\ ${ }^{I}$ Department of Microbiological Surveillance and Research, Statens Serum Institut, DK-2300 S, Copenhagen, Denmark \\ ${ }^{2}$ Copenhagen Wound Healing Centre, Bispebjerg University Hospital, DK-2400 N Copenhagen, Denmark
}

\begin{abstract}
Culture independent methods are used widely in diagnostic laboratories for infectious disease Isolation of genomic DNA from clinical samples is the first and important step in the procedure. Several procedures for extracting DNA from faecal samples have been described, including different mechanical cell disruptors. To our knowledge, the use of TissueLyser as a mechanical disruptor on faecal samples before DNA extraction has not been previously described. The purpose of the study was to implement a method for preparing faecal samples for optimal DNA extraction. Thus, three different procedures for extracting DNA from human faeces were compared. This was done either by using the mechanical disrupter by Mini BeadBeater 8, or the TissueLyser both followed by DNA purification using QIAamp DNA stool MiniKit, in comparison with DNA extractions using QIAamp DNA stool MiniKit without any prior mechanical disruption, according to manufacturer's instructions. The obtained DNA from the three procedures was analysed by DGGE, and the number of bands was compared between each procedure. There was no significant difference between the numbers of bacterial bands obtained from DGGE when using a TissueLyser or Mini BeadBeater 8, so the two different mechanical cell disruptors can be used comparably when isolating bacterial DNA from faecal samples. The QIAamp DNA stool MiniKit alone resulted in a reduced number of bands compared to the two mechanical disruption methods.
\end{abstract}

Keywords: DNA extraction method, faecal samples, Mini BeadBeater 8, TissueLyser .

\section{INTRODUCTION}

Faecal samples contain a large variety of bacteria [1-3]. Using conventional culture techniques, only a small percentage of the bacterial flora is identified [2, 4-5]. With the introduction and implementation of molecular techniques in clinical microbiological diagnostic laboratories, the identification of bacteria present in faecal samples has increased dramatically [5-7]. The isolation of genomic DNA from clinical samples is the first step in studies of microbial diversity using cultivation independent methods. It is, therefore, important to obtain genomic DNA that is representative of the microbial communities present in the samples [8]. However, the use of molecular methods has introduced new problems, such as obtaining sufficient amounts of DNA and of high quality of intact DNA suitable for further processing i.e. PCR, from faecal samples [8-10]. Several procedures for extracting DNA from faecal samples have been described, including different mechanical cell disruptors $[2,11,12]$. None of the described methods have been compared systematically and in the same study using the same samples.

In this study, three methods were compared to evaluate the amount and quality of bacterial DNA extracted from

\footnotetext{
*Address correspondence to this author at the Department of Microbiological Surveillance and Research, Statens Serum Institut, Artillerivej 5, DK-2300 Copenhagen S, Denmark; Tel: +45 3268 3745; Fax: +45 3268 3147; E-mail:kak@ssi.dk

${ }^{+}$present address Peking University First Hospital, Beijing 100034, China
}

human faecal samples. QIAamp DNA stool MiniKit without any prior sample disruption treatment was compared to two mechanical disruption sample preparations, i.e. the Mini BeadBeater 8 and the TissueLyser (Qiagen) used for animal tissue and plant disruption. Both homogenisations were followed by the QIAamp DNA stool MiniKit in order to compare bacterial DNA extractions.

\section{MATERIALS AND METHODS}

\section{Human Faecal Samples}

Fresh faecal samples were obtained from the Laboratory for Enteric Pathogens, Statens Serum Institut, Copenhagen, Denmark, submitted for routine culture. The subjects were between six months and four years of age, and all had diarrhoea; no other clinical information was obtained. Each sample was adjusted to $200 \mathrm{mg}$ wet weight stool before storage at $-80^{\circ} \mathrm{C}$ without glycerol, until processing 24 hours later.

\section{Preparation of Samples}

Each faecal sample was mixed with $1.4 \mathrm{ml}$ ASL (from QIAamp DNA stool MiniKit) in a $2 \mathrm{ml}$ tube and vortexed until the faecal sample was thoroughly homogenized. Samples for the two mechanical treatments were mixed with 0.2 $\mathrm{g}$ sterile zirconia/silica beads (diameter, $0.1 \mathrm{~mm}$, Biospec Product, ROTH, Karlsruhe, Germany). 
The mechanical disruption procedures were: the Mini BeadBeater 8 (BioSpec Products Inc., Bartlesville, Oklahoma, USA) and the TissueLyser system (Qiagen Retsch $\mathrm{GmbH}$, Hannover, Germany). Both procedures were followed by DNA extraction using QIAamp DNA stool MiniKit, (QIAGEN, Hilden, Germany).

\section{The Mini BeadBeater 8}

Bead mill homogenization by Mini BeadBeater 8 , with high speed agitation, was performed on faecal samples as described by [2]. The samples were homogenized for $4 \mathrm{~min}$ at $5000 \mathrm{rpm}$ in a Mini BeadBeater 8 .

\section{TissueLyser}

Bead mill homogenization with the TissueLyser system has not been described for faecal samples previously, therefore optimising the method was necessary.

The TissueLyser is a vibration apparatus providing highthroughput processing for effective disruption of biological samples including bacteria, animal soft tissue and plant tissue [13]. The TissueLyser provides disruption and homogenization achieved through the beating and grinding effect of the beads on the sample material as they shake together in the grinding vessels. Disruption for $4 \mathrm{~min}, 6 \mathrm{~min}$ and $8 \mathrm{~min}$ at $30 \mathrm{~Hz}$ were performed in an adapter set for $2 \times 24$ samples. To prevent variation in sample homogenization, the adaptor was removed from the TissueLyser and disassembled in a reverse order after the first disruption, to ensure a uniform sample homogenisation.

\section{QIAamp DNA Stool MiniKit (Treated and Untreated Samples)}

All samples were centrifuged for 2 minutes at 14,000 rpm prior to the DNA extraction. Extraction of DNA from the supernatant was performed following the protocol of QIAamp DNA stool Mini Kit (QIAGEN, Hilden, Germany) as described by the manufacturer with the following modifications: lysis temperature, $95^{\circ} \mathrm{C}$ [6]. DNA was measured spectrophotometrically (Ultrospec 1100 pro, Amershan Biosciences).

\section{PCR Amplification for DGGE}

The V3 region of the 16S-rRNA with a length of 236 base pairs was amplified with universal bacterial primers. The forward primer PRBA338, positions 338-357 (E. coli numbering) (5'ACTCCTACGGGAGGCAGCAG) [14] and reverse primer PRUN518, positions 518-534 (E. coli numbering) (5'ATTACCGCGGCTGCTGG) $[4,15]$. The forward primer PRBA 338 primers were at the $5^{\prime}$ end labelled with a GC clamp (5'CGCCCGCCGCGCGCGGCGGGCGGGGCGGGGGCACGGGGGG) [4]. All primers were purchased from MWG-BIOTECH AG, Ebersberg, Germany. The final volume of each PCR mixture was $50 \mu \mathrm{l}$. The amplification reaction mixture was as follows: $1.25 \mathrm{U}$ of $\mathrm{Taq}$ DNA polymerase (Promega, Madison, Wis), $5 \mu 1$ 10x PCR buffer, $[1.5 \mathrm{mM} \mathrm{MgCl} 2], 1 \mu \mathrm{l}$ of deoxynucleutide triphosphate at a concentration of $10 \mathrm{mM}, 0.5 \mu \mathrm{M}$ of each primer, 1 $\mu \mathrm{g}$ of DNA template, $0.5 \mu \mathrm{l} \mathrm{BSA}(10 \mathrm{mg} / \mathrm{ml})$. The samples were amplified with a Peltier Thermol Cycler, and the following conditions were used: preheating $94^{\circ} \mathrm{C}$ for $5 \mathrm{~min} ; 30$ cycles of denaturing $94^{\circ} \mathrm{C}$ for $45 \mathrm{sec}$, annealing $55^{\circ} \mathrm{C}$ for 30 sec., elongation $72^{\circ} \mathrm{C}$ for $45 \mathrm{sec}$.

\section{DGGE of PCR Amplicons}

The PCR fragments were separated by DGGE as described by Myuzer [4] with the DCode System as manufacturer prescribes (Bio-Rad Laboratories, Hercules, USA), $8 \%$ Polyacrylamide (vol/vol) (ratio of acrylamide:bisacrylamide [37.5:1]) in $0.5 \times \mathrm{TAE}$ buffer; $(\mathrm{pH} 8.0)$ and using a gradient ranging from $30 \%$ to $65 \%$ denaturant $(100 \%$ denaturant acrylamide corresponds to $7 \mathrm{M}$ urea and $40 \%$ (vol/vol) formamide). The gels were cast using a gradient maker and a pump with a flow speed of $5 \mathrm{ml}$ per min. After polymerization of the denaturing gel (2 hours), a 3\% stacking gel without denaturing chemicals was cast, and an appropriate comb was subsequently inserted and left $10 \mathrm{~min}$ for polymerization. Gels were run at $60^{\circ} \mathrm{C}$ for $16 \mathrm{~h}$ at a constant voltage of $70 \mathrm{~V}$ in $0.5 \times$ TAE buffer. After electrophoresis, gels were stained with SYBR-GOLD (Molecular Probes, Eugene, Org, USA) for $20 \mathrm{~min}$, destained briefly in Milli-Q water and photographed on the Gel Doc system (Biorad).

\section{RESULTS}

\section{DNA Amount Extracted from Faecal Samples}

Faecal samples were divided into equal portions and treated by mechanical disruptors. Different time lengths of disruption were only tested for the TissueLyser, as indicated in materials and methods.

The highest amount of total DNA was obtained, when using the Mini BeadBeater 8 for four minutes and the TissueLyser for eight minutes (data not shown). Using the TissueLyser for more than six minutes showed partial degradation of the genomic DNA on agarose gel. Treatment with TissueLyser for 4 minutes did not yield the same amount of DNA compared to 4 minutes treatment with the Mini BeadBeater 8 (data not shown).

\section{DNA for Further Processing}

The quality of DNA was tested by performing PCRDGGE that targeted all the bacteria present in the faecal sample. Similar results for the two mechanical methods for pre-treatment, i.e. the Mini BeadBeater for $4 \mathrm{~min}$, and TissueLyser for 6 and $8 \mathrm{~min}$ were observed (Fig. 1). The QIAamp stool Minikit alone with no pre-treatment, resulted in a reduced number of bands on the DGGE. Furthermore, the TissueLyser treatment for $4 \mathrm{~min}$ was not sufficient (Table 1).

\section{DISCUSSION}

Studies of intestinal microflora have conventionally been performed by bacterial culturing on selective media [16, 17]. Introduction of molecular techniques, particularly the use of PCR- DGGE, has revealed even more complex microbiological communities to exist in the intestine $[2,5,18]$. Several studies have presented different methods for DNA extraction, such as QIAamp DNA stool MiniKit, Mini Bead Beater 8 [2], and TissueLyser [13]. However, the described methods have not been compared systematically on the same samples and in the same laboratory setting. It is crucial in clinical 


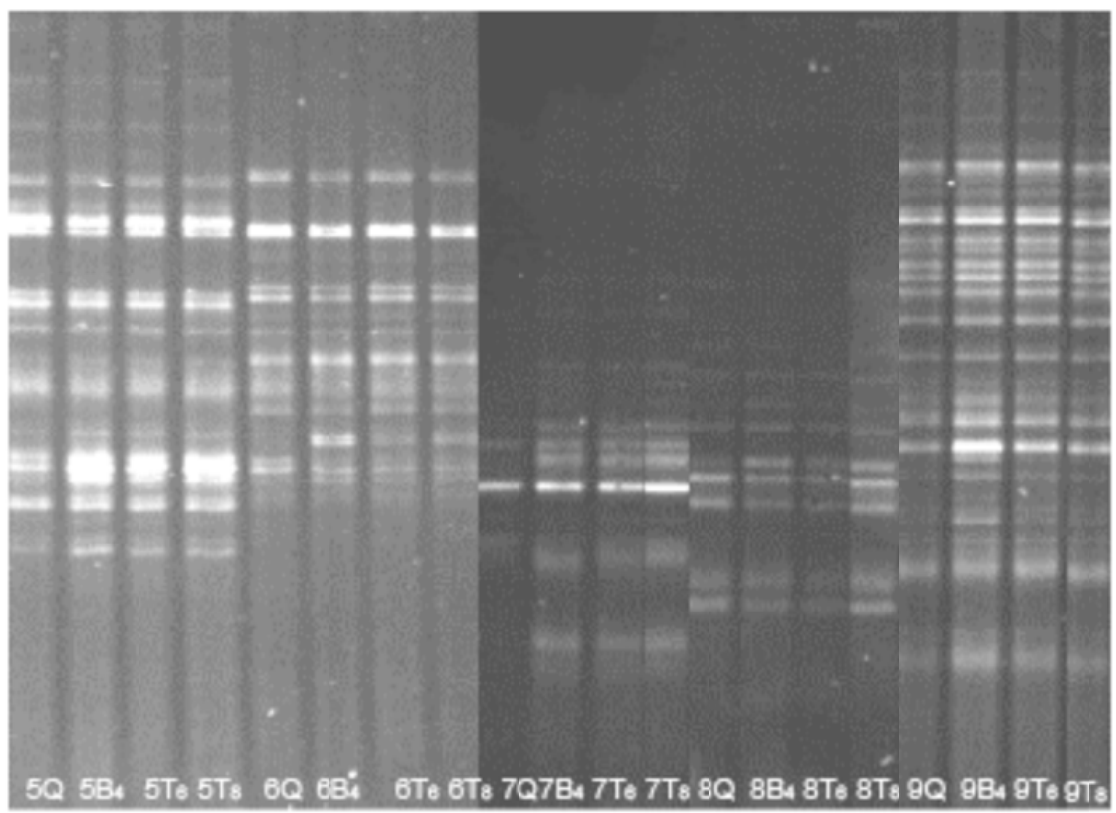

Fig. (1). DGGE on DNA extracted by three different treatment methods from faecal samples. Example of DGGE runs of PCR products from five stool samples by different DNA extractions. DGGE profiles (30-65\% denaturant) from faecal samples on DNA extracted by three different treatment methods and treatment times. (B) pre-treatment by Mini BeadBeater $8(\mathbf{T})$ pre-treatment by TissueLyser, $(\mathbf{Q})$ no pretreatment. All subsequent DNA extractions were performed by the QIAamp DNA stool MiniKit. The agitation time was 4 minutes for the Mini BeadBeater 8, and 6 minutes and 8 minutes for the TissueLyser. (The picture is compiled from two gel images, aligned according to the reference lane comprising an internal standard (not shown)).

Table 1. Number of DGGE Bands Obtained by PCR after Different Physical Disruption of the Samples

\begin{tabular}{|c|c|c|c|c|c|}
\hline \multicolumn{2}{|c|}{ DGGE bands } & Min & Max \\
\hline Tissue Treatment & $\mathbf{n}$ & mean & 6 & 2 & 20 \\
\hline \hline Qiagen only & 9 & 11 & 7 & 3 & 6 \\
\hline Beadbeater 4 min & 9 & 12 & 5 & 16 \\
\hline TissueLyser 4 min & 4 & 9 & 7 & 26 \\
\hline TissueLyser 6 min & 5 & 15 & 6 & 10 \\
\hline TissueLyser 8 min & 5 & 15 & 24 \\
\hline
\end{tabular}

DGGE profiles (30-65\% denaturant) from 9 faecal samples on DNA extracted by three different treatment methods. All subsequent DNA extractions were performed by the QIAamp DNA stool MiniKit.n: number of treated samples; mean: mean number of DGGE bands; Std dev: standard deviation of DGGE bands; min: minimum of DGGE bands; max: maximum of DGGE bands.

microbiology to find a reproducible procedure for obtaining sufficient amounts of DNA, with no degradation products, from even a very small sample.

The results presented in this study show that a mechanical pre-treatment before using the QIAamp DNA stools MiniKit facilitates an efficient homogenizing and lysis, leading to the recovery of an increased amount of bacterial DNA (Table 1 and Fig. 1).

In this study, the TissueLyser showed similar results in disrupting genomic DNA from faecal samples compared to the Mini BeadBeater 8. We demonstrated that the DGGE bands obtained by treatment of 8 min with Mini BeadBeater were similar to those achieved when agitating $4 \mathrm{~min}$ and 6 min, although there was some level of DNA degradation in longer treatments $(8 \mathrm{~min})$. The two types of mechanical dis- ruptions are both fast and with the same hands on time. The Mini BeadBeater 8 can handle 8 samples simultaneously, whereas the Tissuelyser handles 1-52 or 1-96 samples simultaneously. However, to prevent variation in sample homogenization, the adaptors have to be disassembled after the first disruption and the order reversed.

The study showed that the TissueLyser (6 min processing) is comparable with the Mini BeadBeater 8 (4 min processing) with regard to the quality and number of the DGGE bands (Table $\mathbf{1}$ ).

Furthermore, the mechanical disruption of the faecal samples before using the QIAamp DNA stool MiniKit improved the amount and quality of DNA and thereby the diversity in the bacterial bands in DGGE. We conclude that both mechanical devices can be used with comparable re- 
sults, favouring the Mini BeadBeater 8 for a small number of samples, while the TissueLyser is recommended for processing of a large number of samples.

\section{CONFLICTS OF INTERESTING}

The authors have no conflicts of interest to report.

\section{ACKNOWLEDGMENTS}

Researcher Dr. Nan Li was partially financed by the Chinese Government.

\section{REFERENCE}

[1] Magne F, Suau A, Pochart P, Desjeux JF. Fecal microbial community in preterm infants. J Pediatr Gastroenterol Nutr 2005; 4: 38692.

[2] Favier CF, Vaughan EE, De Vos WM, Akkermans AD. Molecular monitoring of succession of bacterial communities in human neonates. Appl Environ Microbiol 2002; 68: 219-26.

[3] van Tongeren SP, Slaets JP, Harmsen HJ, Welling GW. Fecal microbiota composition and frailty. Appl Environ Microbiol 2005; 71: 6438-42.

[4] Muyzer G, de Waal EC, Uitterlinden AG. Profiling of complex microbial populations by denaturing gradient gel electrophoresis analysis of polymerase chain reaction-amplified genes coding for 16S rRNA. Appl Environ Microbiol 1993; 59: 695-700.

[5] Murray CS, Tannock GW, Simon MA, et al. Fecal microbiota in sensitized wheezy and non-sensitized non-wheezy children: a nested case-control study. Clin Exp Allergy 2005; 35: 741-5.

[6] Nielsen DS, Moller PL, Rosenfeldt V, Paerregaard A, Michaelsen $\mathrm{KF}$, Jakobsen M. Case study of the distribution of mucosaassociated Bifidobacterium species, Lactobacillus species, and other lactic acid bacteria in the human colon. Appl Environ Microbiol 2003; 69: 7545-8.

[7] Tannock GW, Munro K, Bibiloni R, et al. Impact of consumption of oligosaccharide-containing biscuits on the fecal microbiota of humans. Appl Environ Microbiol 2004; 70: 2129-36.
[8] Forney LJ, Zhou X, Brown CJ. Molecular microbial ecology: land of the one-eyed king. Curr Opin Microbiol 2004; 7: 210-20.

[9] Bell MJ, Ternberg JL, Feigin RD, et al. Neonatal necrotizing enterocolitis. Therapeutic decisions based upon clinical staging. Ann Surg 1978; 187: 1-7.

[10] Zoetendal EG, Ben Amor K, Akkermans AD, Abee T, De Vos WM. DNA isolation protocols affect the detection limit of PCR approaches of bacteria in samples from the human gastrointestinal tract. Syst Appl Microbiol 2001; 24: 405-10.

[11] Zoetendal EG, Akkermans AD, De Vos WM. Temperature gradient gel electrophoresis analysis of 16S rRNA from human fecal samples reveals stable and host-specific communities of active bacteria. Appl Environ Microbiol 1998; 64: 3854-59.

[12] Donskey CJ, Hujer AM, Das SM, Pultz NJ, Bonomo RA, Rice LB. Use of denaturing gradient gel electrophoresis for analysis of the stool microbiota of hospitalized patients. J Microbiol Methods 2003; 54: 249-56.

[13] Nakaune R, Nakano M. Efficient methods for sample processing and cDNA synthesis by RT-PCR for the detection of grapevine viruses and viroids. J Virol Methods 2006; 134: 244-9.

[14] Lane D.J. 16S/23S rRNA sequencing. In: E.Stackebrandt and M Goodfellow, editor. Nucleic acid tecniques in bacterial systematics. John Wiley \& Sons Ltd.,West Sussex, United Kingdom, 1991: 11575.

[15] Ovreas L, Forney L, Daae FL, Torsvik V. Distribution of bacterioplankton in meromictic Lake Saelenvannet, as determined by denaturing gradient gel electrophoresis of PCR-amplified gene fragments coding for 16S rRNA. Appl Environ Microbiol 1997; 63: 3367-73.

[16] Watanabe S, Narisawa $\mathrm{Y}$, Arase S, et al. Differences in fecal microflora between patients with atopic dermatitis and healthy control subjects. J Allergy Clin Immunol 2003; 111: 587-91.

[17] Sepp E, Julge K, Mikelsaar M, Bjorksten B. Intestinal microbiota and immunoglobulin $\mathrm{E}$ responses in 5-year-old Estonian children. Clin Exp Allergy 2005; 35: 1141-6.

[18] Tannock GW. Exploring the relationships between intestinal microflora and inflammatory conditions of the human bowel and spine. Antonie Van Leeuwenhoek 2002; 81: 529-35. 